\title{
Results of Combining Phosphorylase Kinase Inhibition with Removal of Precipitating Factors in Large Cohort of Psoriatic Patients: A Proof of Concept Study ${ }^{*}$
}

\author{
Madalene C. Y. Heng ${ }^{1,3 \#}$, Judith Harker ${ }^{2}$, Ming K. Heng ${ }^{1,3}$ \\ ${ }^{1}$ UCLA School of Medicine, Los Angeles, USA; ${ }^{2}$ Department of Geriatrics, VA Medical Center, Sepulveda, USA; ${ }^{3}$ Center for Fam- \\ ily Health, Oxnard, California, USA. \\ Email: "madaleneheng@aol.com
}

Received June 12 $2^{\text {th }}, 2011$; revised July 21 $1^{\text {st }}, 2011$; accepted August $2^{\text {nd }}, 2011$.

\begin{abstract}
* $^{*}$
Background: Phosphorylase kinase (PhK) activity is induced by injurious stimuli, which is known to precipitate psoriasis. We had previously reported that elevated PhK activity in psoriatic epidermis correlated with increased psoriatic activity, and that suppression of PhK activity by its inhibitor, curcumin gel, correlated with disease resolution. Objective: We evaluated the efficacy of a strategy of combining PhK inhibition by topical curcumin with elimination of PhK-generating precipitating factors from various injurious stimuli in producing improvement of psoriatic activity, aiming at complete resolution. Patients and Methods: We studied a cohort of 647 consecutive patients with mild to severe psoriasis in a single center. Our therapeutic regimen consisted of curcumin gel, topical steroids, strict avoidance of contact allergens, avoidance of dairy products in lactose-intolerant patients, and treatment of infections to eliminate bacterial superantigens. Results: PASI scores at 0 wk was $24.7+/-17.1(S D), n=647$. PASI scores improved significantly at 4 weeks to $11.5+/-8.1(n=638 ; p<0.0001)$, at 8 weeks to $4.5+/-4.2(n=636, p<0.0001)$, and at 16 weeks to $0.9+/-2.5(n=641, p<0.0001)$. At 16 weeks, $72.2 \%$ of patients were completely clear of psoriatic activity $(P A S I=0)$. Conclusion: Our results indicate that a regimen of PhK inhibition by topical curcumin with elimination of PhK-generating factors is effective in producing significant reduction of psoriatic activity at 16 weeks, with complete clearance of psoriasis in $72.2 \%$ of patients.
\end{abstract}

Keywords: Psoriasis, Phosphorylase Kinase, Bacterial Superantigens, Contact Antigens, Lactose Intolerance

\section{Introduction}

Psoriasis is a proliferative skin disease [1-3] that has an inflammatory [4,5] and genetic basis [6-10]. Based on familial studies as well as genome-wide scans of sibling pairs, susceptibility loci have been mapped to the alleles located on the distal end of chromosome 17 (17q) [6,7] in some individuals, as well as on 16q [7-9] in others. In addition, genome-wide scans have identified the association of psoriasis with Histocompatibility antigens, cytokine-mediated inflammatory pathways (IL-23) and nu- clear factor-kappa B (NF-kB) pathways [10,11]. NF-kB is a transcription activator that is activated by injurious stimuli.

While psoriasis has a genetic basis [6-10], the clinical

"Abstract presented at the 22nd World Congress of Dermatology, Seoul, Korea May 2011. manifestation of the disease is often precipitated by a number of injurious stimuli which cause inflammatory skin injury and activate cell proliferation through the NF-kB signaling pathways. These include various allergens, infections [12-16] and even physical trauma, such as tape-stripping $[17,18]$. It has been shown that the injury $[17,19]$ activates immune cells $[17,19]$, including dendritic cells [19] and T lymphocytes, [19] with induction of inflammatory cytokines, in particular tumor necrosis factor- $\alpha(\mathrm{TNF} \alpha)$ [18], resulting in growth factor-mediated epidermal proliferation [18]. In psoriasis, the role of infections and bacterial superantigens [12-16, 20-25] in aggravating psoriasis has increasingly been recognized. In particular, Streptococcus pyogenes and Staphylococcus aureus isolates from patients with pso- 
riasis have been found to possess genes that code for superantigens [20]. We have previously reported the association between Staphylococcus aureus infection and erythrodermic spread of the disease [12].

This observation was supported by a recent study showing high prevalence of Staphylococcus aureus in psoriatic patients [16]. Additionally, the role of injury in priming the immune response for enhanced $\mathrm{T}$-cell response against bacterial superantigens has also been observed [21], emphasizing the synergistic role of skin injury, contact allergy and bacterial superantigens in the final phenotypic expression of the psoriatic process. More recently, we have also identified additional superantigens, such as lipopolysaccharides (LPS) and heat shock proteins (HSP60) in an animal model for lactose intolerance [26].

Phosphorylase kinase is a unique enzyme in which the spatial arrangements of the specificity determinants can be manipulated so that $\mathrm{PhK}$ can alter the size and shape of the substrate binding sites $[27,28]$. This allows the enzyme to transfer high energy phosphate bonds from ATP to substrates of different specificities, such as serine threonine and tyrosine moieties, involving $\mathrm{PhK}$ in phosphorylation of moieties of multiple specificities, such as is required for the activation of NF-kB. Since genome-wide scans have identified the association of psoriasis with NF-kB-pathways, it is also significant that curcumin, a phosphorylase kinase inhibitor, has been shown to suppress the activity of NF-kB $[33,34]$.

In psoriatic epidermis, elevated $\mathrm{PhK}$ has been shown to correlate with both increased phosphorylation events and increased psoriatic activity [29], with significantly higher PhK levels observed in both involved and uninvolved skin of active, untreated psoriasis, and a reduction of $\mathrm{PhK}$ activity in both involved and uninvolved skin of healing psoriasis [29]. Using topical curcumin [30], a selective and non-competitive inhibitor of $\mathrm{PhK}$ [31], we observed that a reduction of $\mathrm{PhK}$ activity by curcumin correlated with clinical resolution of psoriasis as shown by reduction of parakeratosis (histological marker of psoriasis), decreased expression of HLA-DR antigens (marker of TNF $\alpha$ activity) [32], and marked reduction in the density of Ki-67+/PCNA+ keratinocytes (marker of psoriatic epidermal proliferation). Since it is well-known that psoriasis is induced by injury, the findings that $\mathrm{PhK}$ inhibition is necessary for resolution of psoriasis, coupled with the fact that PhK activity is induced by injury, suggest a mediating role for PhK between the events precipitated by tissue injury and the manifestations of clinical psoriasis. It is of interest that increased TNF $\alpha$ expression has been observed in psoriasis induced by tapestripping injury [18].
Tournier et al. [35,36] has observed decreased binding of cAMP analog to the Type II regulatory subunit of cAMP-dependent protein kinase in psoriatic cells, with abnormalities in retinoylation of the Type II cAMPbinding regulatory subunit of cAMP-dependent protein kinase in psoriatic tissue. Since the activity of cAMP protein kinase is triggered by binding of cAMP to its regulatory subunits, an alteration in binding properties of the regulatory subunits would alter the activity of cAMP protein kinase on their target enzymes. Cho-Chung et al. [37] have provided evidence that two isoforms, the RI and RII regulatory subunits of cAMP-dependent protein kinase, have opposite roles in cell growth and differenttiation, with RI being growth stimulatory and RII being growth inhibitory. It is possible that the RI and RII regulatory subunits of cAMP-dependent protein kinase may achieve their effects through mediation by phosphorylase kinase. We suspect that the inhibitory role of Type II cAMP-dependent protein kinase may be achieved through "switching-off/deactivation of phosphorylase kinase, and that the stimulatory role of Type I cAMP-dependent protein kinase may be achieved through "switching-on" phosphorylase kinase activity. We further suspect that fluctuations in the activity of cAMP-dependent protein kinases and their regulatory subunits may be triggered by injury to cell membranes in psoriasis.

We, therefore, postulate that the role of $\mathrm{PhK}$ in modulating the clinical manifestations of psoriasis is likely related to the following: $\mathrm{PhK}$ may be manipulated by various cAMP protein kinases to function as a "switchon" and "switch-off" mechanism for wound healing. Following injury, $\mathrm{PhK}$ is activated by Type I cAMPdependent protein kinase, which causes a conformational change in the molecule, exposing further sites on the molecule for phosphorylation reactions, thus serving as a "switch-on mechanism" for NF-kB-dependent signaling pathways involved in wound healing. These NF-kB-dependent pathways are inhibited by the $\mathrm{PhK}$ inhibitor, curcumin $[33,34]$. After the wound is healed, $\mathrm{PhK}$ is deactivated by Type II cAMP-dependent protein kinase through another conformational change in the molecule, thus serving as a switch-off mechanism for wound healing. The regulatory subunits for cAMP-dependent protein kinases have been mapped to alleles on the distal end of the 17th chromosome (17q) [38], while the $\beta$-subunit of $\mathrm{PhK}$, which contains the receptor site for Type II cAMP-protein kinase, has been mapped to $16 \mathrm{q}[39,40]$. It is of interest that alleles from both 17q [6,7] and 16q [7-9] have been identified as susceptibility loci from genomewide scans and scans from psoriatic families.

We suspect that the persistently elevated levels of $\mathrm{PhK}$ activity found in psoriatic epidermis [29,30] reflects an 
abnormal switch-off mechanism for the elevated levels of $\mathrm{PhK}$ activity induced by injurious stimuli found in genetically susceptible psoriatic individuals. This failure to down-regulate the activity of this enzyme after injury may be responsible for the persistently abnormal histological and biochemical findings in psoriatic lesions.

Based on the above, we postulate that a therapeutic regimen that targets the elimination or attenuation of a number of injury factors related to the precipitation of psoriasis should result in improvement of psoriatic activity. This included avoidance of contact allergens, treatment of bacterial superinfection with long term antibiotics, inhibition of TNF $\alpha$ by topical corticosteroids [4143] and inhibition of PhK by topical curcumin [30,31]. This proof-of-concept paper reports the results of this therapy in a large cohort of consecutive psoriatic patients in whom the disease had failed to respond to the conventional topical and systemic therapy.

\section{Patients and Methods}

The patient population consisted of a personal series of consecutive psoriatic patients seen in one of the author's $(\mathrm{MCYH})$ consultative dermatology practice between January 2003 to April 2009. There were 647 patients, M $=48.5 \%, \mathrm{~F}=51.5 \%$, mean age $45.2 \pm 24.6 \mathrm{yr}$ (mean \pm SD). The patients were referred because of clinical failure to respond to conventional therapy used during the period of the study. They had failed on one or more of the following: topical steroids, methotrexate, etretinate, and biologics (etanercept, infliximab and adalimumab). All the patients were on topical steroids (corticosteroids) and/or calcipotriene or Dermazinc preparations, and 10\% were additionally on one or more of the others. The baseline characteristics of the patient population are summarized in Table 1.

The curcumin gel used in this study is a propriety preparation classified in the United States as a cosmetic. All patients were counseled on the therapeutic regimen and the rationale for its use. In particular, they were aware of the status of the curcumin gel, and the fact that the therapeutic regimen was used with the aim of ameliorating the psoriatic lesions that had failed to respond to previous treatment. Data related to the demographics, clinical characteristics and therapeutic response were obtained from charts without notation of patient identity. Because of this, and the fact that the analysis was retrospective and observational, informed consent was not applicable.

\section{Protocol}

At initial consultation, a detailed history and physical examination was performed, and the skin involvement documented by clinical assessment and photography for Psoriasis Area Severity Index (PASI) scoring. Patients were also seen at the 4 th week, 8th week and 16 th week for assessment of their PASI scores. During this followup period, adjustments to allergen assessments and antibiotic treatment were made, if necessary. The reproducibility of PASI scores was measured in a subgroup of 20 subjects. The scores were measured on two separate occasions one week apart with the identity of the subjects removed. The two measurements were averaged, and the percent deviation of each measurement from the average score was calculated. The mean percentage deviation was $0.6 \% \pm 0.8 \%$ (mean $\pm \mathrm{SD}$ ). The percent deviations ranged $0 \%-2.7 \%$.

Bacterial colonization of psoriatic skin: The affected skin was cultured using a culture tube in gel transport medium. The cotton swab was first dipped in the gel, and vigorously rubbed over the psoriatic skin, targeting excoriated and pruritic areas, and sent for bacterial culture and sensitivities.

Identification of precipitating factors and aggravating factors: Depending on the sites of involvement, potential allergens were identified as follows:

1) Scalp: Pityosporum ovale (seborrheic dermatitis), black/brown (paraphenylene diamine) hair dyes, nickel from coins and keys through touching with the fingers, and Staphylococcus aureus/MRSA infection. Overgrowth of Pityosporum ovale may be worsened by stress and by lactose intolerance.

2) Trunk and Limbs: Elastic antioxidants in rubber wet suits, clothing (shirts, blouses, slacks, socks and underwear); paraphenylene diamine dyes in black/brown clothing, socks/stockings, belts and wet diving suits; trivalent chromates in leather products (belts, boots, shoes, upholstery); nickel from coins and keys, buttons; Staphylococcus aureus or MRSA infection.

3) Palms and Soles: Trivalent chromates in leather footwear, elastic antioxidants; neoprene glues, paraphenylene diamine dyes, elastic antioxidants, formaldehyde and anti-fungal products, leather or black steering wheel cover, leather gloves, latex gloves, glues/dyes/elastic antioxidants/trivalent chromates in tennis rackets and golf clubs, nickel from coins and keys; hair dyes, with contact made during hair washing; other products containing trivalent chromates such as cement, gasoline, brake fluid, motor oils, printer's ink, electrolysis solutions; Staphylococcus aureus and MRSA infection.

4) Flexural Areas, Axilla, Groin, Buttocks: Candida albicans, elastic antioxidants, deodorants, black/brown dyes, lactose intolerance, bacterial superinfection.

5) Guttate psoriasis: This is known to be precipitated by streptococcal infections (in susceptible patients with HLA-B16) involving the throat, sinuses, ears, or perianal skin. Because the perianal erythema is usually associated 
with colonic inflammation in lactose intolerant individuals, patients with involvement of the buttocks and perianal skin were put on a lactose free diet.

6) Lactose Intolerance: Lactose intolerance was suspected to be present when there was perianal erythema or dermatitis. In addition, symptoms of constipation, diarrhea, hemorrhoids, diverticulitis, colitis, known colon polyps, sebaceous hyperplasia and mild acanthosis nigricans were also considered likely presumptive evi- dence for lactose intolerance.

Antibiotics: All patients were initially started on oral cephalexin, which was continued until clearance unless resistant strains were cultured. The antibiotics were changed as indicated by the culture results. Patients who were culture positive for Staphylococcus aureus and resistant to two or more antibiotics tested, were treated with two sensitive antibiotics. Methicillin resistant staphylococcus aureus (MRSA) were initially treated with two sensitive antibiotics (usually trimethoprim-sulfamethoxazole and clindamycin). MRSA infections that failed these combinations were treated patients with intravenous vancomycin. The antibiotics were continued until the patients were clinically clear.

Antifungals: Oral fluconazole $200 \mathrm{mg}$ weekly were given for scalp psoriasis and flexural psoriasis, and continued until clearance.

Chlorox baths: All patients were put on chlorox baths daily. They used one eighth to one quarter of a $5 \mathrm{oz}$ cup of chlorox bleach dissolved in a half-filled full bath of water. Patients soaked themselves for 5 minutes. They were told to pour water all over their heads and exposed trunk and limbs, to clean the inside of their nares with the bath water, but to avoid wetting their ear canals.. After the chlorox bath, they showered off the chlorine with soap and water, washed their hair with shampoo, and dried themselves with a fresh towel daily. They also changed clothes, socks, bed-sheets and pillow cases daily. Chlorox baths were used to allow the chlorine in the bath water to penetrate the bacteria-containing porous psoriatic scales.

Topical Preparations: For the scalp, patients used clobetasol solution $0.05 \%$ each morning. For the trunk and limbs, they used a combination of clobetasol cream $0.05 \%$ mixed with equal parts of ketoconazole cream $2 \%$ morning and noon. For the face and flexural areas, they used a combination of triamcinolone cream $0.1 \%$ mixed with equal parts of ketoconazole cream $2 \%$ morning and noon. For resistant plaques, they may use clobetasol cream $0.05 \%$ undiluted, and occasionally clobetasol $0.05 \%$ solution or spray.

Curcumin gel: Curcumin gel was used for all involved areas after the chlorox bath and shower at night. In order to increase penetration of curcumin gel through the air-filled porous psoriatic scales that retard penetration of topical preparations, $70 \%$ rubbing (isopropyl) alcohol was used to wet the scales and displace the air within the air-filled spaces within the scales. While the scales were still wet, curcumin was massaged into the wet alcohol, which enabled the curcumin gel to penetrate through and under the psoriatic scales.

Avoidance of allergens: Patients were repeatedly instructed to avoid elastic/latex/spandex clothing, socks and gloves. They used clear vinyl gloves under their latex gloves or leather gloves. They also use clear vinyl gloves when pumping gas. Coins and keys were put in plastic bags, and patients wash their hands after touching coins and keys. They avoided stretch clothing and socks. Boxer shorts with ties were encouraged, but patients were permitted to use elastic underwear that was lined by three layers of non-stretch material separating the elastic from the skin. They inserted plastic wrap/bag between the skin of their feet and socks, or between the socks and shoes whenever applicable. Black/brown clothing and hair dyes were avoided. They may use vegetable dyes such as henna, or peroxide.

Follow-up visits: Patients were advised to discontinue biologics, methotrexate and etretinate therapy, but were continued on their topical steroid preparations. Most of the patients had, on their own accord, stopped biologics because of response failure prior to the visit. The patients were reassessed at 4 weeks, 8 weeks and 16 weeks. Clinical evaluation and repeat photography for PASI scores were performed at each return visit. Skin lesions were re-cultured if indicated and the appropriate antibiotics prescribed. A second antibiotic was added if culture results showed development of resistant strains. During these visits, deviations from the regimen were corrected, including delays in starting curcumin gel, and failure to comply with avoidance of elastic antioxidants, nickel or black dyes, or lactose containing foods.

\section{Data Analysis}

Data was analyzed using SPSS for Windows. Continuous data was analyzed using the appropriate significance tests for parametric and non-parametric data. Categorical data were analyzed using the chi-square and related tests, and non-parametric data by the Wilcoxon signed ranks and related tests. Parametric analysis with paired-t tests or repeated measures analysis of variance was done whenever possible. However, the data for PASI scores were not normally distributed and did not meet assumptions of parametric analysis. Therefore, the non-parametric Wilcoxon signed ranks tests for paired samples were done to compare baseline PASI scores with scores at 4, 8 and 16 
weeks. Results were considered significant when $p<$ 0.05 for the two-tailed tests.

\section{Results}

\subsection{Baseline Characteristics of the Patient Population}

The baseline characteristics of the patient population at the start of treatment are summarized in Table 1. Of the 647 patients, $51.5 \%$ were females, and $48.5 \%$ males. The age was $45.2 \pm 23.6(\mathrm{SD})$ years. The patients were divided into quartiles by age to assess whether response to treatment was age related. The average PASI score before start of treatment was $24.7 \pm 17.4$ (SD), with a range of $4-72$. All the patients were on topical steroids at the start of treatment, and $10 \%$ were on topical steroids with recent use of one or more of the following: methotrexate, etretinate, and biologics. Skin cultures were positive in $62.9 \%$ of patients; of these $90 \%$ were Staphylococcus aureus (including 6\% MRSA), 9\% streptococcus sp., and $1 \%$ mixed bacteria (Aeromonas, Serratia).

\subsection{Assessment of Improvement in PASI Scores with Therapy over 16 Weeks}

Treatment with our regimen resulted in significant improvement in psoriasis measured by PASI score, as shown in Figure 1. Before treatment $(n=647)$, the PASI score was $24.73 \pm 17.09$ (mean, SD). After treatment, the scores were as follows: at 4 weeks $(n=638), 11.45 \pm$ $8.06(p<0.0001)$; at 8 weeks $(n=636), 4.46 \pm 4.24(p<$ $0.0001)$; and at 16 weeks $(n=641), 0.93 \pm 2.55(p<$ $0.0001)$.

We also examined the improvement in PASI scores by computing the slope of the scores for each person, assum-

Table 1. Baseline characteristics of patient population.

\begin{tabular}{|c|c|}
\hline Number of patients & $n=647$ \\
\hline Males: & $48.5 \%$ \\
\hline Females: & $51.5 \%$ \\
\hline Age in years: & $45.2 \pm 23.6($ mean $\pm \mathrm{SD})$ \\
\hline$<20 \mathrm{yr}$ & $n=120$ \\
\hline $21-40 \mathrm{yr}$ & $n=137$ \\
\hline $41-60 \mathrm{yr}$ & $n=227$ \\
\hline$>60 \mathrm{yr}$ & $n=163$ \\
\hline PASI scores ( 0 week) & $24.7 \pm 17.4(\mathrm{SD}) ;$ range $4-72$ \\
\hline $\begin{array}{l}\text { Topical agents (steroids, } \\
\text { calcipotriene, zinc preparations) }\end{array}$ & $n=647$ \\
\hline $\begin{array}{l}\text { Methotrexate, etretinate, } \\
\text { biologics with or without } \\
\text { topical agents }\end{array}$ & $n=65$ \\
\hline Infection (culture positive) & $\begin{array}{c}62.9 \% \text { - S. aureus } 90 \% \\
(\mathrm{MRSA} 6 \%)\end{array}$ \\
\hline Streptococcus $9 \%$, mixed & $1 \%$ \\
\hline
\end{tabular}

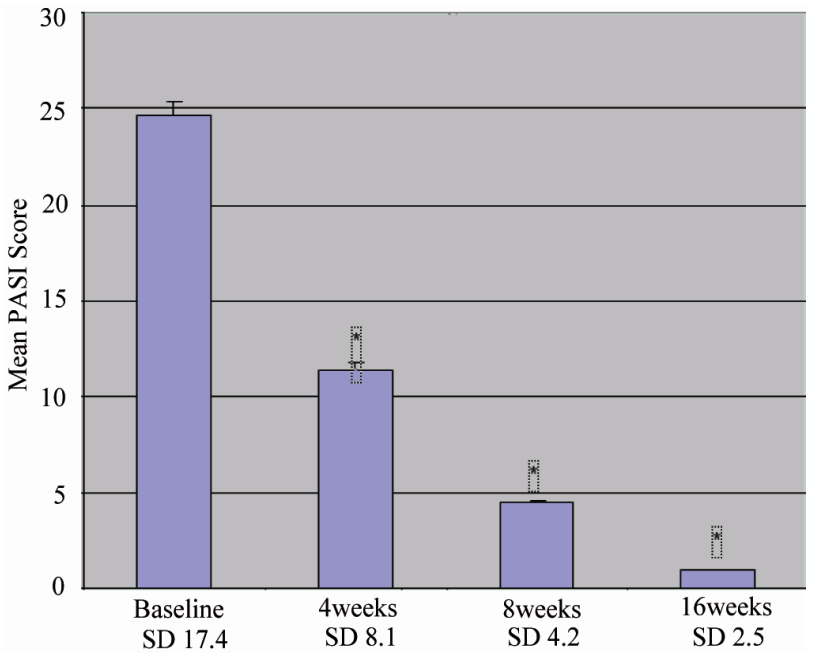

Figure 1. shows the improvement of PASI scores with time $(0,4,8$ and 16 weeks) in our cohort of 647 patients treated with our protocol. The $y$ axis shows the mean PASI scores at each time point with standard errors of the mean. Standard deviations are provided below each time point on the on the $x$-axis. The improvement in PASI scores was significantly different at 4,8 and 16 weeks, with $p<0.0001\left({ }^{*} p<\right.$ 0.0001 compared to baseline).

ing a linear model of change with time, and using theslope as a measure of change. The results are shown in Figure 2. In this analysis, a negative slope indicates improvement, and the value indicates the mean improvement in PASI score over the 16 weeks of follow up. A slope of 0 means no improvement, and a positive slope means worsening with treatment. This analysis showed that no patient had slope of 0 (no improvement) or a positive slope (worsening of score with treatment). The mean slope of the group of patients was significantly different from zero, indicating that the PASI score of the group significantly improved $(p<0.0001)$ during the period of study. In addition, the slope was highly correlated with initial baseline score, $(r=0.988, p<0.0001)$, meaning that patients with the worst baseline PASI score had the highest rate of improvement.

\subsection{Assessment of Proportion of Patients Healed}

The proportion of patients that had clinically healing judged by a PASI score of $0($ PASI $=0)$ is shown in Figure 3. This analysis shows that the number of healed patients increased with time, and was over $70 \%$ after 16 weeks. Patients that had PASI $=0$ was $0.03 \%$ at the 4 th week, $6.5 \%$ at the 8 th week, and $72.2 \%$ at the 16 th week. We also analyzed the data taking into account the number of patients that did not present for follow up at the designated weeks ( 9 at 4 weeks, 11 at 8 weeks, and 6 at 16 weeks) and the percentage of patients with PASI = 


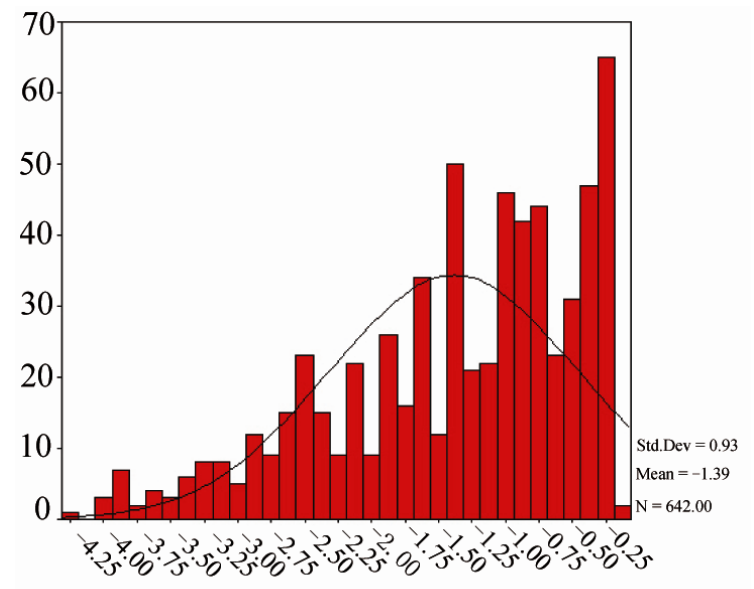

Slope PASI in $16 \mathrm{wk}$

Figure 2. shows the improvement of PASI scores as assessed by slope. The $y$ axis displays the number of patients ( $y$ axis) grouped according to improvement in PASI scores at 16 weeks. The $x$ axis shows the degree of slope negativity, which reflects the degree of improvement. The more negative the slope, the greater the improvement. This analysis showed that no patient at 16 weeks had a positive slope (worsening disease) or a zero slope (no change in disease activity).

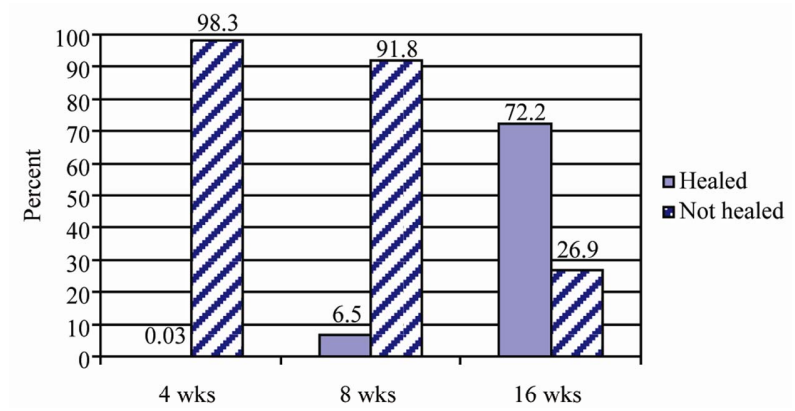

Figure 3. shows percent improvement in PASI scores (y axis) at 4,8 and 16 weeks ( $x$ axis), with the percentage of healed patients $($ PASI $=0)$ in solid light blue columns, and percentage unhealed patients (PASI $>0$ ) in hatched columns. At 16 weeks, the percentage of healed patients was $72.2 \%$.

0 was unchanged.

\subsection{The Effect of Gender on Treatment Response}

The effect of gender on response to therapy is shown in Table 2, and the results suggest that females appear to respond better to the treatment regimen compared to males. PASI scores were similar in males and females at baseline to 8 weeks. However, at 16 weeks, the PASI was significantly lower in females compared to males: $0.65 \pm 1.72$ vs $1.23 \pm 3.18(p<0.005)$. In addition, the percentage of females who appeared healed with a PASI score of 0 at 16 weeks was significantly higher than males: $77.0 \%(n=254)$ vs $68.5 \%(n=213)$.

\subsection{The Effect of Age on Treatment Response}

The effect of age on treatment response is shown in Table 3 . The patients were divided into 4 quartiles of age, and the results showed while all groups responded to treatment with lower PASI score at 16 weeks, the youngest quartile $<20$ years appeared to improve the most. At 16 weeks, the PASI score in this quartile was significantly lower than in the other 3 quartiles $(p<$ $0.0001)$. In addition, an analysis of the slope showed that this age quartile had a slope negativity for PASI scores that was significantly greater than the other 3 groups ( $p<$ $0.024)$. These results indicate that patients under 20 years of age appeared to have the greatest rate and degree of improvement to treatment with our regimen compared to older patients. However, while the data does suggest that while the younger patients tend to heal more and faster, the relationship between age and treatment response is not monotonic, and the age quartiles above 20 years showed no effects of age with response to therapy.

\subsection{The Effect of Infection on Treatment Response}

We examined the treatment response by presence and absence of infection on skin cultures. Of the total group of patients (Table 4), 37.1\% $(n=240)$ had negative skin

Table 2. Comparison of PASI scores in males and females at $0,4,8$ and 16 weeks.

\begin{tabular}{cccc}
\hline & $\begin{array}{c}\text { Female } \\
\text { Mean (SD) }\end{array}$ & $\begin{array}{c}\text { Male } \\
\text { Mean (SD) }\end{array}$ & $p$ value \\
\hline Baseline & $23.73(16.29)$ & $25.79(17.86)$ & 0.216 \\
4 weeks & $11.00(7.46)$ & $11.94(8.63)$ & 0.372 \\
8 weeks & $4.11(3.54)$ & $4.83(4.85)$ & 0.161 \\
16 weeks & $0.65(1.72)$ & $1.23(3.18)$ & 0.005 \\
Slope PASI scores & $-1.35(0.91)$ & $-1.42(0.095)$ & 0.414 \\
\hline
\end{tabular}

$p$ values are derived from nonparametric analysis by Mann-Whitney $\mathrm{U}$ test.

Table 3. Comparison of PASI scores with treatment time in the four age groups.

\begin{tabular}{cccccc}
\hline & $\begin{array}{c}<20 \mathrm{yr} \\
(n=120)\end{array}$ & $\begin{array}{c}21-40 \mathrm{yr} \\
(n=137)\end{array}$ & $\begin{array}{c}41-60 \mathrm{yr} \\
(n=227)\end{array}$ & $\begin{array}{c}>60 \mathrm{yr} \\
(n=163)\end{array}$ & $\begin{array}{c}p \\
\text { value }\end{array}$ \\
\hline Baseline & 27.19 & 22.48 & 24.21 & 25.53 & 0.064 \\
& $(16.66)$ & $(15.29)$ & $(18.29)$ & $(16.95)$ & \\
4 & 11.43 & 10.74 & 11.58 & 11.90 & 0.738 \\
weeks & $(7.40)$ & $(6.82)$ & $(9.07)$ & $(8.04)$ & \\
8 & 3.74 & 4.22 & 5.08 & 4.33 & 0.256 \\
weeks & $(3.53)$ & $(3.28)$ & $(5.36)$ & $(3.56)$ & \\
16 & 0.34 & 0.68 & 1.57 & 0.67 & $<0.0001$ \\
weeks & $(1.26)$ & $(1.18)$ & $(3.72)$ & $(1.81)$ & \\
& & & & & \\
Slope & -1.55 & -1.28 & -1.31 & -1.46 & 0.024 \\
& $(0.94)$ & $(0.86)$ & $(0.95)$ & $(0.93)$ & \\
\hline
\end{tabular}

$n=$ number of patients. PASI scores are mean $\pm \mathrm{SD} . p$ values are derived from non-parametric Kruskal-Wallis test for multiple independent groups. 
cultures (culture-negative group), while 62.9\% $(n=407)$ had positive skin cultures (culture-positive group). Of the positive cultures, $90 \%$ were coagulase positive staphylococcus (Staphylococcus aureus and MRSA), 9\% streptococcus sp, and $1 \%$ mixed bacteria.

The culture-positive group had significantly higher baseline scores (PASI 29.6 \pm 17.3) than the culturenegative group (PASI $16.5 \pm 13.0 ; p<0.0001$ ). The culture-positive group was also significantly younger (42.4 $\pm 25.3 \mathrm{yr})$ than the culture negative group $(50.1 \pm 19.5 \mathrm{yr}$; $p<0.0001)$

There was no difference in the response to total therapy as shown by PASI scores at 16 weeks between the culture positive (PASI $1.13 \pm 3.04$ ) and culture negative groups (PASI $0.58 \pm 1.29$ ). This lack of difference in the response was shown both with regard to the percentage that appeared healed at 16 weeks and the slope of the improvement rate. At 16 weeks, $76.3 \%$ of the culture-negative group was healed (PASI $=0$ ), while $70.8 \%$ of the culture-positive group were healed ( $p=0.413)$. Figure 4 shows the slope of the change in PASI scores after treatment in the culture-positive and culture-negative groups; the slope between the two groups was similar.

At 16 weeks, the group of patients who did not heal and had greater residual disease as judged by a PASI score of $>5$, contained a significantly greater number of culture positive patients $(4 \%, n=16)$ compared to the number of culture negative patients $(0.4 \% ; n=1 ; p=$ 0.018 ). This suggests that infection is possibly a cause of the failure to completely heal with treatment in these patients, but the umbers are probably too small to draw any definitive conclusions.

\section{Clinical Patients with Lactose intolerance}

\subsection{Patient 1}

Patient 1 (Figures 5(a)-(b)) is an 80 year old female with total body psoriasis (PASI 70) for 60 years, with culture positive MRSA from truncal skin, only cleared after 12 weeks of intravenous vancomycin, followed by 4 weeks of oral clindamycin $300 \mathrm{mg}$ bid and trimethoprim/sul

Table 4. PASI Scores and age of patients with infection and no infection.

\begin{tabular}{cccc}
\hline & $\begin{array}{c}\text { No infection } \\
(n=240) \\
\text { Mean (SD) }\end{array}$ & $\begin{array}{c}\text { Infection } \\
(n=407) \\
\text { Mean (SD) }\end{array}$ & $p$ value \\
\hline $\begin{array}{c}\text { Baseline } \\
\text { PASI }\end{array}$ & $16.5(13.0)$ & $29.6(17.3)$ & $<0.0001$ \\
$\begin{array}{c}\text { PASI at } \\
\text { 16 wks } \\
\text { Age }\end{array}$ & $0.58(1.29)$ & $1.13(3.04)$ & 0.056 \\
\hline
\end{tabular}

$n=$ number of patients. $p$ value derived from chi-square analysis.

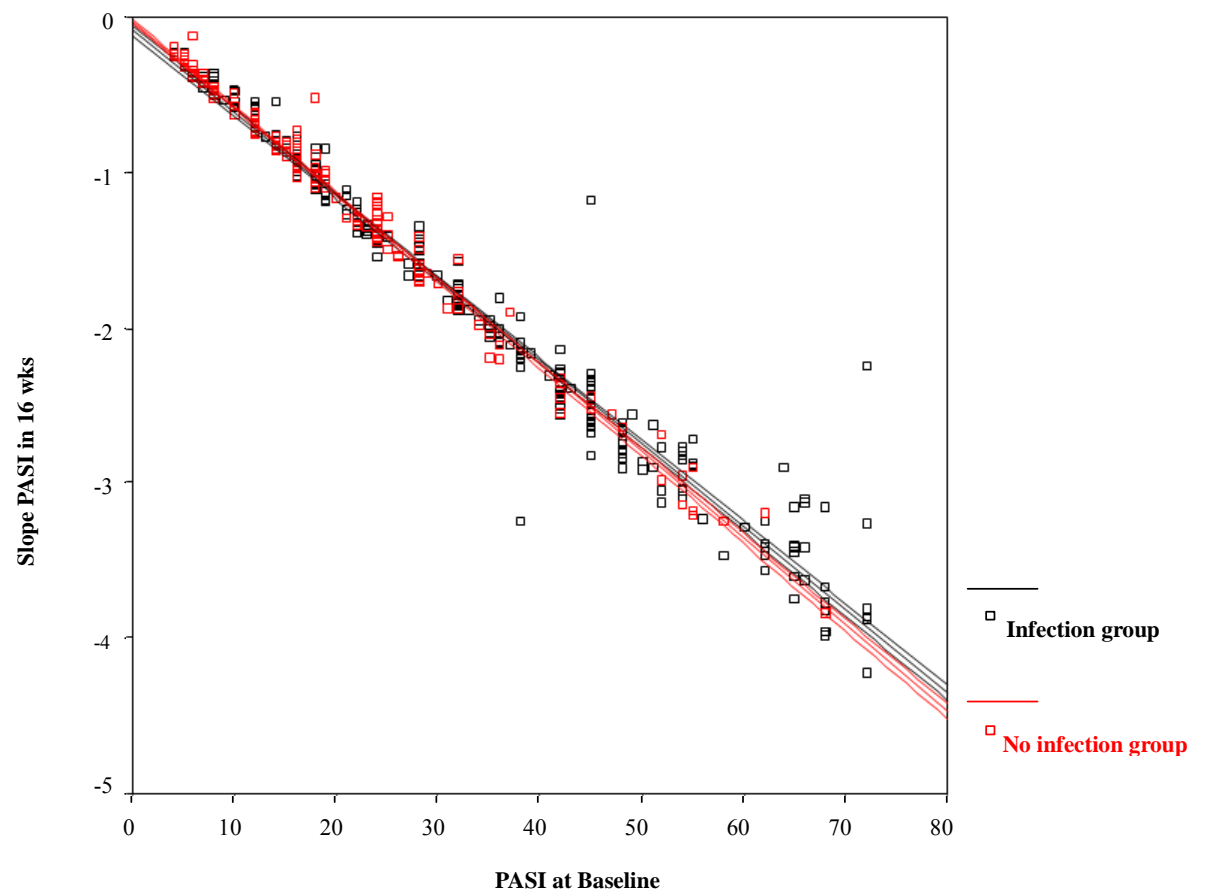

Figure 4. shows the mean improvement in PASI scores at 16 weeks as determined by the slope (y axis) as measured against severity of psoriasis at baseline determined by PASI scores ( $x$-axis). The culture-positive patients are shown in black, while the culture-negative patients in red. The regression lines for the infection group (black) and no infection group (red) are nearly identical between the two groups, indicating that at 16 weeks, the two groups healed at similar rates. 


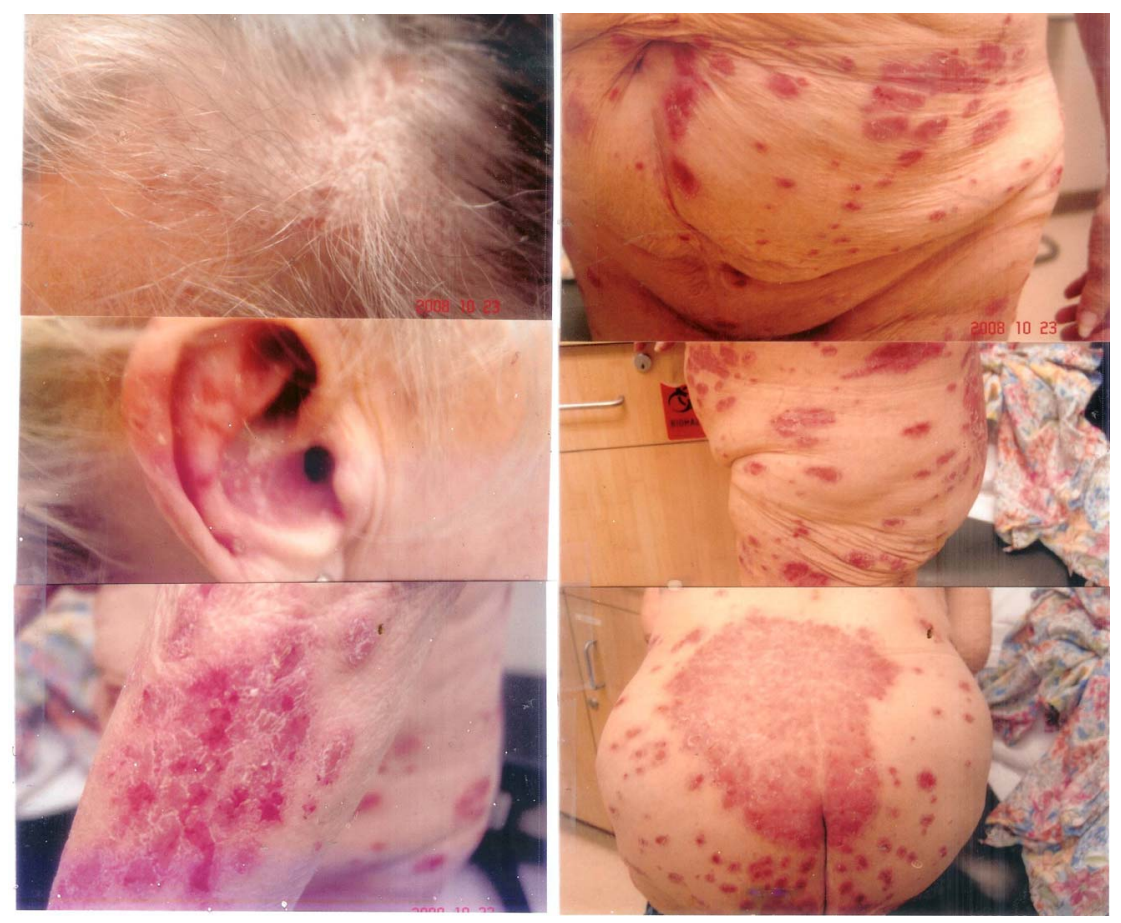

(a)

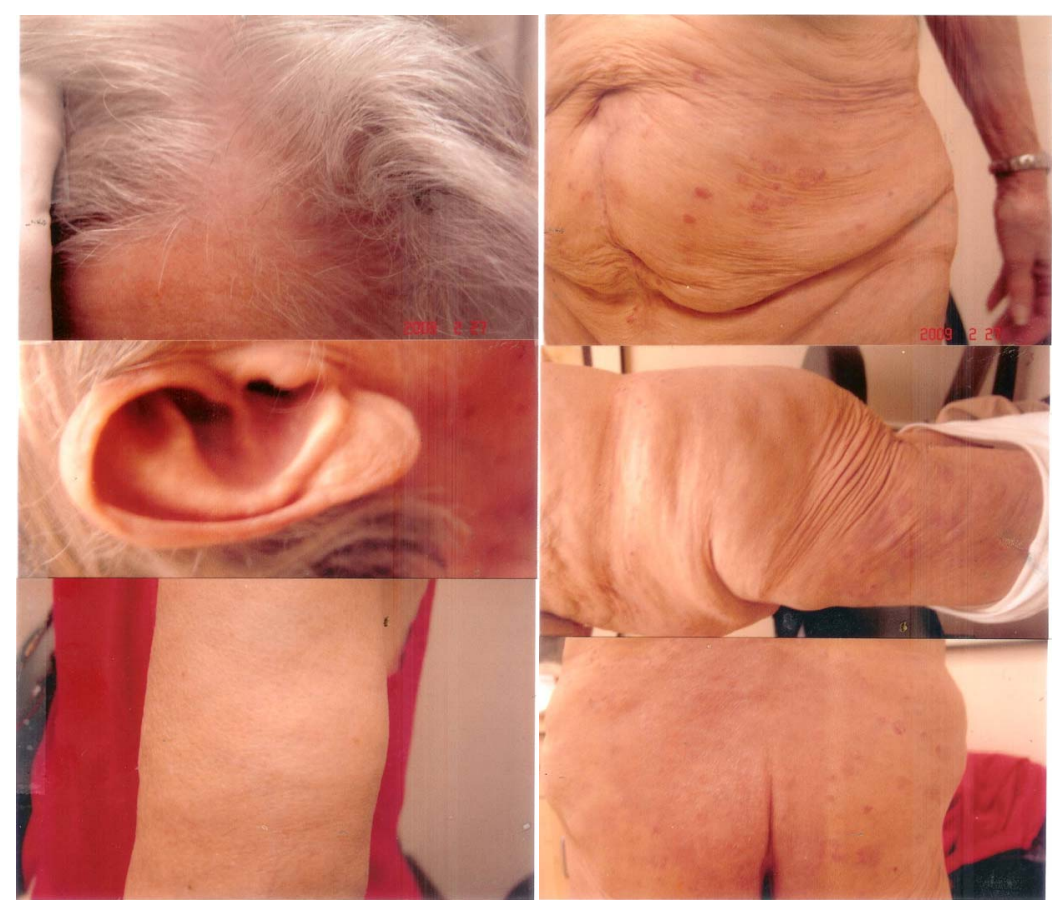

(b)

Figure 5. (a) 80 year old female with 60 years of generalized psoriasis (PASI 70) with contact allergy to paraphenylene diamine hair dyes and black/brown clothing, elastic antioxidants, and culture positive MRSA infection. She is also lactose intolerant (note buttock lesions); (b) same patient who eventually cleared completely after 4 months with avoidance of hair dyes and black/brown clothing, elastic clothing, and long-term antibiotics (intravenous vancomycin (12 weeks) and oral clindamycin and Bactrim for 4 weeks), topical clobetasol cream during the day and curcumin gel after a chlorox bath at night. She was on a lactose free diet. She remains clear with no topical or systemic therapy after 26 months. 
famethoxazole (one DS tablet twice daily). Additional aggravating factors in this patient included lactose intolerance, contact allergy to paraphenylene hair dyes and black/brown clothing, allergy to elastic antioxidants from bras, stockings, underwear and stretch clothing. She was tapered off her topical clobetasol creams followed by taper of curcumin gel. She remains clear on no therapy when followed up 26 months later. She is still on a lactose free diet.

\subsection{Patient 2}

The psoriatic patient in Figures 6(a)-(b) is a 38 year old man who is lactose intolerant, with perianal psoriasis, which was culture-positive for both Staphylococcus aureus and Streptococcus sp. He had generalized guttate and plaque psoriasis with involvement of flexural areas (groin, navel). Aggravating factors include lactose intolerance and contact allergy to elastic antioxidants and paraphenylene diamine dyes. He may also have been allergic to nickel from handling coins and keys. He was put on oral keflex $500 \mathrm{mg}$ (2 capsules twice daily), oral

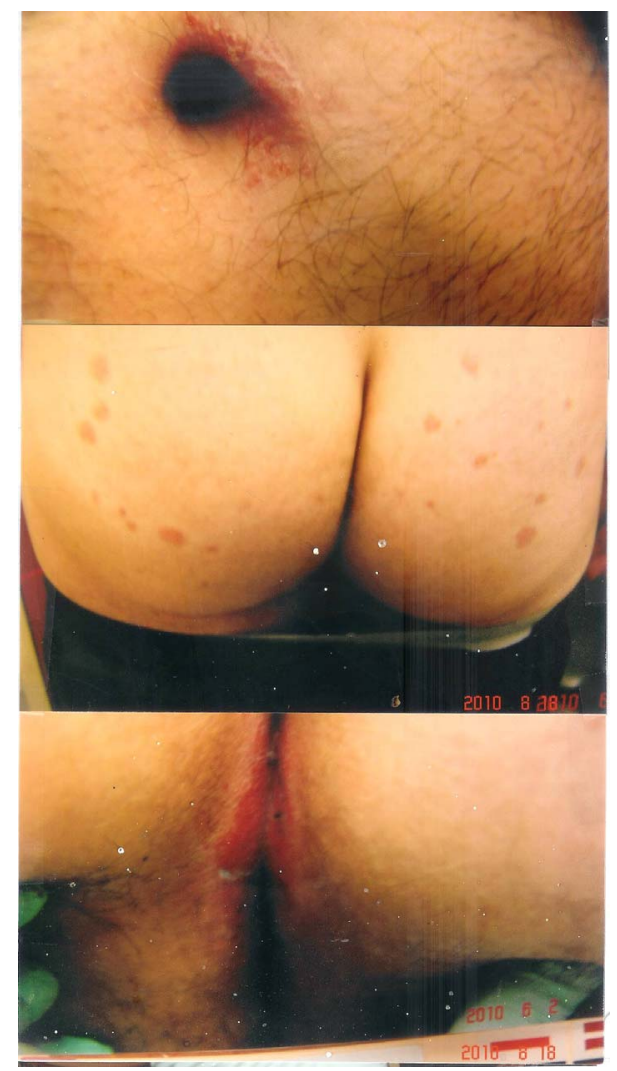

(a)
Diflucan (200 mg weekly), clobetasol cream $0.05 \%$ mixed with equal parts of ketoconazole cream $2 \%$ for the trunk and limbs, and a mixture of triamcinolone cream $0.1 \%$ mixed with equal parts of ketoconazole cream $2 \%$ morning and noon, and curcumin gel after a chlorox bath at night. He did not clear until he went on a lactose-free diet (Figure 7(b)).

\subsection{Patient 3}

Patient 3 is a 48 year old man with wide-spread psoriasis over the trunk and limbs. He had flexural involvement with psoriasis of the intergluteal cleft which grew a positive culture for Staphylococcus aureus, and Streptococcal sp. He had a colostomy for ulcerative colitis. He was treated with oral keflex (500 mg, 2 capsules twice daily), oral Diflucan $200 \mathrm{mg}$ weekly, clobetasol cream $0.05 \%$ mixed with ketoconazole cream $2 \%$ for the trunk and limbs, and triamcinolone cream $0.1 \%$ mixed with ketoconazole cream $2 \%$ for the flexural areas during the day. At night, after a chlorox bath, he used curcumin gel. Although he was much improved after the antibiotic

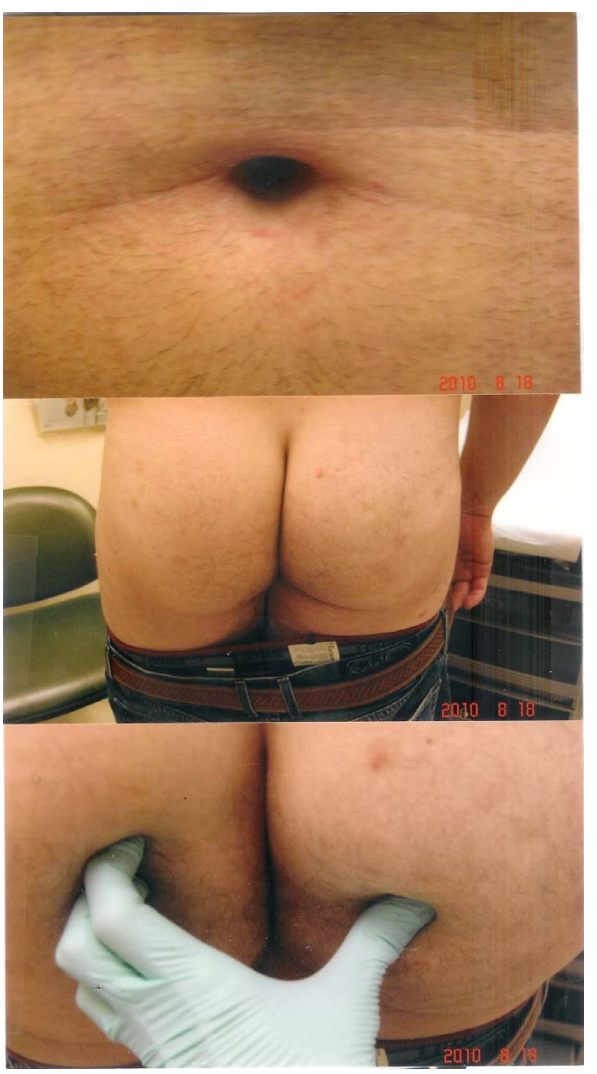

(b)

Figure 6. (a) Patient with generalized guttate and plaque psoriasis with perianal involvement, culture positive for both Streptococcus sp and Staphylococcus aureus. Note guttate lesions over his buttocks and flexural involvement.of his navel; (b) same patient with clearance of his psoriasis only after institution of a lactose free diet. He was also put on oral keflex, oral diflucan, topical steroid creams during the day, and curcumin gel after a chlorox bath at night. 
treatment, the residual perianal psoriasis did not clear until he went on a lactose free diet (Figure 7, lower panel).

\section{Discussion}

\subsection{Paradigm}

In this study, we have postulated a paradigm (Figure 8), linking the precipitating and aggravating factors that lead to worsening psoriasis through $\mathrm{PhK}$ activity. It includes the role of inflammatory cytokines, in particular TNF $\alpha$ generated by both antigens and superantigens as a mediator between the precipitating factors and $\mathrm{PhK}$, which may explain the observed beneficial effects of topical corticosteroid preparations in our treatment regimen. We used this paradigm to serve as a basis for a therapeutic regimen, and report on the results of the treatment as a proof of concept study.

\subsection{Role of Infections and Bacterial Superantigens in Psoriasis}

The results of our study are consistent with the notion that bacterial superantigens played a significant role in amplifying TNF $\alpha$-dependent phenotypic expression of psoriasis. We found that over $62 \%$ of psoriatic patients had positive cultures for superantigen-producing bacteria. Of these, staphylococci, such as Staphylococcus aureus and MRSA, were found in $90 \%$ of culture-positive psoriatic skin. The association of Staphylococcus aureus in skin disease, including psoriasis, was reported as early as 1986 [12]. Our current findings are consistent with a recent study, in which Staphylococcus aureus was cultured from $64 \%$ of lesional psoriatic skin, $14 \%$ of non-lesional skin, and $50 \%$ of the nares [16]. The report also postulated that the Staphylococcus aureus was responsible for superantigen production in the psoriatic patients [16]. However, we also cultured superantigen-producing streptococci in $10 \%$ of patients. We suspect that the proportion of streptococcal cultures was low because while we did routinely cultured psoriatic pla-

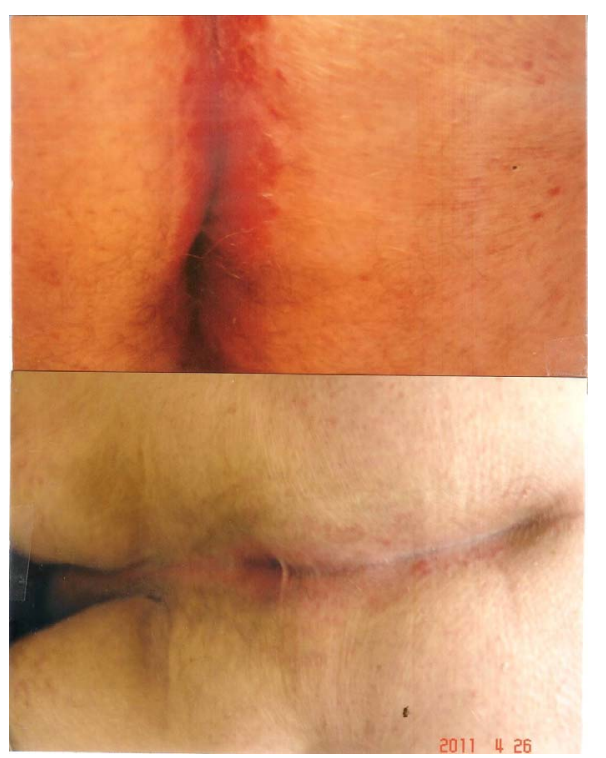

Figure 7. Psoriatic patient with ulcerative colitis with perianal psoriasis culture positive for both Staphylococcus aureus and streptococcal sp. (upper panel). The psoriasis was persistent and did not clear until he was put on a lactose free diet (lower panel).

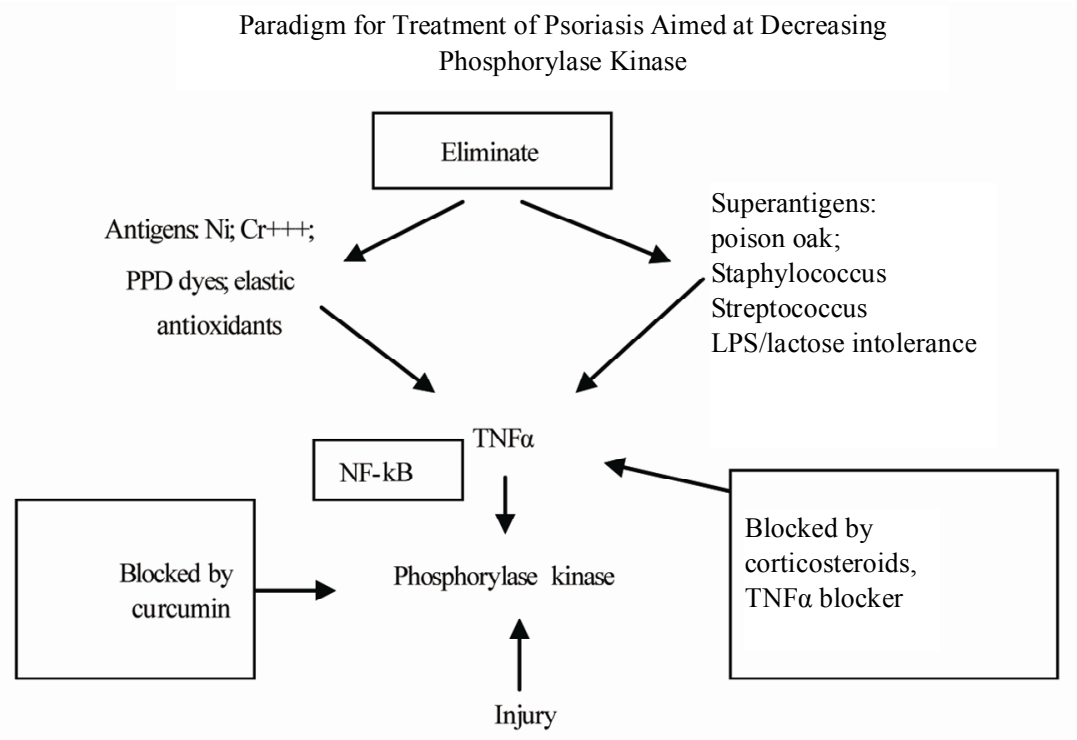

Figure 8. Paradigm for treatment of psoriasis. 
ques, we did not routinely culture the perianal areas, where most of positive streptococcal cultures were obtained. We also suspect that streptococcal colonization, most-likely from a perianal source, may have played a role in our culture-negative psoriatic patients who responded to oral cephalexin. This inference is supported by reports of close associations between streptococcal $[14,15,20,22-25]$ and staphylococcal $[12,13,16]$ infections and psoriatic activity. Streptococcal infections, frequently from perianal sources in adults [44] have been reported to be associated with guttate psoriasis [45]. Although streptococcal throat infections have long been known to exacerbate guttate psoriasis, it is only recently that streptococcal infections have also been shown to exacerbate chronic plaque psoriasis [15]. Histocompatibility antigens, such as HLA-B16 and HLA-C have been associated with the susceptibility to streptococcal infections perhaps through binding of bacterial antigens to the histocompatibility complex, and HLA-C in particular, has been associated with guttate psoriasis [45-48].

Our observation that the culture positive group had significantly higher baseline PASI scores $(29.6 \pm 17.3)$ compared to the culture-negative group $(16.5 \pm 13.0, p<$ 0.001 ) strongly suggests that bacterial superantigens play an important role in disease severity. Despite this difference at baseline, the response to treatment in both groups measured by PASI scores was similar at 16 weeks, probably because of antibiotic treatment. Because the psoriatic disease tended to recur with premature withdrawal of oral antibiotics in both culture-positive groups, our protocol included treatment of infected groups by antibiotics until normalization of the skin barrier. We also observed that oral antibiotics were essential to obtain continued improvement as long as psoriatic lesions were still present, but could be discontinued without disease recurrence (1 - 5 year follow-up; Heng MCY unpublished data) once the patients were totally clear. In some patients, improvement was observed initially, with relapses associated with cultures of resistant Staphylococcus aureus colonies. Such patients improved with combinations of multiple antibiotics.

Long term antibiotic therapy has also been observed by others to benefit patients with chronic plaque psoriasis $[49,50]$. Saxena and Dogra, after treating their patients with intramuscular benzathine penicillin 2.4 million units fortnightly for 48 weeks, and 1.2 million units monthly for 2 years, reported improvement after 12 weeks of therapy, with excellent improvement after 2 years of therapy [49]. In a recent study, Saxena and Dogra, observed improvement with 48 weeks of azithromycin in a controlled study. Recurrences were observed when azithromycin was stopped after 48 weeks in $16.6 \%$, and after 1 year of therapy in $20 \%$. Improvement was observed in these patients with reinstitution of therapy [50]. Since both streptococcal $[22-25,51,52]$ and staphylococcal superantigens $[12,13,16]$ are believed to play a role in aggravating chronic plaque psoriasis, both bacteria have to be treated.

\subsection{Role of Contact Allergens in Psoriasis}

The common contact allergens in our patients include nickel, paraphenylene diamine dyes, elastic antioxidants and trivalent chromates. In our patients paraphenylene diamine dyes (hair dyes and clothing) and elastic antioxidants were the most common precipitating and aggravating factors in our patients. Unlike superantigens which bind outside the MHC (major histocompatibility complex) binding groove of antigen presenting cells, and area able to activate large numbers of T cells $(20 \%)$ with secretion of large quantities of $\mathrm{TNF} \alpha$, contact allergens usually bind only to the MHC binding groove of antigen presenting dendritic cells, which present these allergens to the $\mathrm{T}$ cell receptor for antigen recognition. The ensuing $\mathrm{T}$ cell activation results in activation of only $0.0001 \%$ of the $\mathrm{T}$ cells, results in secretion of correspondingly small quantities of TNF $\alpha$. Nevertheless, the pruritic contact eczema when scratched results in damaged stratum corneum, with serum oozing to the skin surface. The serum not only provides a culture medium for Staphylococcus aureus, but also contains essential proteases necessary to release $\mathrm{T}$ cell mitogens (superantigens) from the bacterial cell membrane [12]. As discussed above, the bacterial superantigens are likely to significantly aggravate psoriatic activity by stimulating the expression of large amounts of TNF $\alpha$.

Contact allergens may serve also to prime the immune system for specialized cytokine secretion by converting non-stimulated naïve cells into memory cells. For example, it has also been shown that the superantigens of Staphylococcus aureus stimulate the production of IL-17 from memory but not naïve $T$ cells [53], suggesting that contact allergens may prime $\mathrm{T}$ cells to produce $\mathrm{IL}-17$ when further stimulated by staphylococcal superantigens. This observation emphasizes the importance of avoiding contact allergens in the management of psoriasis.

\subsection{Role of Lactose Intolerance in Psoriasis}

Lactose intolerance was extremely common in our patients $(>60 \%)$. The presence of lactose intolerance was strongly suspected in our patients with perianal erythema. These patients frequently have associated streptococcal infections and lesions over their buttocks, thighs and legs. The importance of lactose intolerance in our patient population is suggested by the observation that some 
patients can only be cleared with abstinence of dairy products (Figures 5-7), and relapse of their psoriasis occurred with intake of lactose with accompanying perianal dermatitis. Even in patients with colostomy for ulcerative colitis, the perianal psoriasis could only be cleared with a lactose free diet (Figure 7). As far as we know, this is the first report of aggravation of psoriasis by lactoseintolerance.

In lactose intolerant individuals, the undigested sugar interferes with colonic bacterial function and survival and probably causes events that lead to inflammatory changes and heightened immune responses that affect psoriatic activity. Experimentally, the presence ofundigested carbohydrate in the colon increases the osmotic pressure in the colon and results in colitis with release of lipopolysaccharide (LPS) bacterial membranes from dead and dying bacteria [26] Lipopolysaccharides have been shown to induce Th17-polarized response by dendritic cells through I $\kappa \mathrm{B} \alpha$ kinase and p38 MAPK phosphorylation [54]. Lipopolysaccharides are also capable of inducing TNF $\alpha$-primed dendritic cells to produce IL-23 and induce resting CD4 cells to secrete IL-17, resulting in secretion of high levels of TNF $\alpha$ by the inflammatory cells $[55,56]$. It is of interest that IL-23 and Th17 cells have been found to be important in gut inflammation, 56 while blockade of IL-23 and TNF $\alpha$ by monoclonal antibodies result in reversal of the colonic inflammation [58,59]. It is also significant that the involvement of the IL-23/Th17 pathway has been considered an important pathway in the psoriatic process $[60,61]$.

\subsection{Role of Phosphorylase Kinase Inhibtion in Resolution of Psoriatic Lesions}

The psoriatic lesion is dependent on the activity of two components: a) the psoriatic component, and b) the inflammatory component. While the inflammatory component, which is dependent on a number of cytokines, including TNF $\alpha$, may be observed in many inflammatory skin diseases, including contact dermatitis and atopic dermatitis, the psoriatic component is unique to the genetic psoriatic tendency, which has been linked to abnormalities in 16q [7-9] and 17q [6,7].

At the cellular level, the psoriatic component is manifested by the conversion of the unstimulated keratinocyte, which is PCNA (proliferating cell nuclear antigen) negative, into its psoriatic or proliferative counterpart, the PCNA+ cell. The presence of the PCNA+ cell is identified by the immunocytochemical marker, $\mathrm{Ki}-67+$, and is unique only to the psoriatic disease. The PCNA positivity confers upon the psoriatic keratinocyte the ability to produce epidermal turnover times of once every 4 days, compared to the normal turnover times of once every 60 days. In addition, the PCNA+/Ki-67+ psoriatic keratinocytes are responsible for the well-defined lesions of both plaque and guttate psoriasis. We have previously shown a correlation of psoriatic activity with $\mathrm{PhK}$ activity, [29] as well as correlation of $\mathrm{PhK}$ to the $\mathrm{Ki}-67+$ cells in psoriatic epidermis [30]. Furthermore, we have shown that suppressing $\mathrm{PhK}$ activity using its selective inhibitor, curcumin, in a topical gel preparation, was effective in producing resolution of psoriasis, [30] as well as suppression of $\mathrm{CD} 8+\mathrm{T}$ cell density [30]. Of interest is the observation by Ortega et al. [61] that IL-17 producing CD8+ lymphocytes from psoriatic plaques secrete Th-17-related cytokines. Furthermore, our results of this study provides further proof-of-concept data to our previous observation that topical steroids alone, through $\mathrm{TNF} \alpha$ inhibition, is not effective in producing complete and sustainable resolution of psoriasis, and that to clear psoriasis completely, the addition of a $\mathrm{PhK}$ inhibitor, such as curcumin gel, is also necessary. Our current observation provides added credence to our prior observation that a return to normal numbers of Ki-67+ keratinocytes associated with therapy by curcumin gel was necessary for complete resolution of psoriasis [30].

\subsection{Results of Treatment and Comparison with Other Reported Therapies}

The results of this study show that a high proportion (over $72 \%$ ) of psoriatic patients with mild to severe psoriasis can be cleared within 16 weeks of treatment with a protocol consisting of $\mathrm{PhK}$ inhibition with topical curcumin (anti-psoriatic treatment), topical corticosteroid preparations (anti-inflammatory treatment), as well as strict removal of precipitating and aggravating factors (PhK-generating). These results compare favorably with other studies showing $16.7 \%$ of adalimumab-treated patients, $7.3 \%$ of methotrexate-treated patients, and $1.9 \%$ of placebo-treated patients achieving complete clearance at 16 weeks [61]. The PASI scores in our patients $(24 \pm$ 17.09) were similar to the adalimumab-treated group (20.2 \pm 7.5$)$, and methotrexate group (19.4 \pm 7.4$)$ [61]. In a recent study comparing two etanercept regimens, $46 \%$ of patients receiving $50 \%$ etanercept twice weekly by subcutaneous injection received a physicians' global assessment of "clear or almost clear" at 12 weeks compared to $32 \%$ for the $50 \mathrm{mg}$ weekly dosage [61], with $56 \%$ clearance for the biweekly dosage at 24 weeks compared to $50 \%$ for the weekly dosage.61 In this study, we separated patients that were totally clear (PASI 0) from those that were "almost clear" (PASI 1-5), and the $72.2 \%$ reflects only patients that were totally clear (PASI 0 ) at 16 weeks. If confirmed by others, our results may be clinically important in view of the known difficulty in 
completely clearing psoriatic lesions [63].

\section{Conclusions}

The results of this study show that a protocol consisting of topical curcumin, topical steroids, together with treatment of bacterial superantigens, avoidance of contact allergens and lactose containing foods, is effective in producing resolution of psoriasis in over $70 \%$ of patients within 16 weeks. Our data support the important role of $\mathrm{TNF} \alpha$-generating superantigens (staphylococcal, streptococcal and LPS), and the priming role of contact allergens in the psoriatic process. Our data also support the hypothesis that the two candidate psoriatic genes [6-9] (mapped to $17 \mathrm{q}$ and $16 \mathrm{q}$ ) regulate NF-kB pathways modulated through $\mathrm{PhK}$ activity, and that psoriasis may be the result of failure to deactivate the elevated $\mathrm{PhK}$ activity induced by injurious stimuli, resulting in persistent epidermal proliferation though NF-kB/TNF $\alpha[64,65]$ dependent pathways. We emphasize that while the treatment protocol has strong biologic rationale and plausibility, the results of this report are from an uncontrolled, retrospective and observational analysis, and should be regarded as a proof-of-concept study. Randomized controlled trials to confirm the results are needed.

\section{REFERENCES}

[1] E. J. Van Scott and T. M. Ekel, "Kinetics of Hyperplasia in Psoriasis," Archives of Dermatology, Vol. 88, No. 4, 1963, pp. 373-381.

[2] S. Gelfant, "The Cell Cycle in Psoriasis: A Reappraisal," British Journal of Dermatology, Vol. 95, No. 6, 1976, pp. 577-579. doi:10.1111/j.1365-2133.1976.tb07028.x

[3] J. G. Krueger, P. Berstresser, J. L. Nicholas and J. J. Voorhees, "Psoriasis," Journal of the American Academy of Dermatology, Vol. 11, No. 5, 1994, pp. 937-947. doi:10.1016/S0190-9622(84)80018-3

[4] B. S. Baker, A. E. Swain, L. Fry and H. Valdimarsson, "Epidermal T Lymphocytes and HLA-DR Expression in Psoriasis," British Journal of Dermatology, Vol. 110, No. 5, 1984, pp. 555-564. doi:10.1111/j.1365-2133.1984.tb04678.x

[5] B. S. Baker and L. Fry, "The Immunology of Psoriasis," British Journal of Dermatology, Vol. 126, No. 1, 1992, pp. 1-9. doi:10.1111/j.1365-2133.1992.tb08394.x

[6] J. Tomfohrde J. A. Silverman A, B. Barnes, M. A. Fernandez-Vina, M. Young, D. Lori, L. Morris, et al., "Gene for Familial Psoriasis Susceptibility Mapped to the Distal end of Human Chromosome 17q," Science, Vol. 264, No. 5162, 1994, pp. 1141-1145. doi:10.1126/science.8178173

[7] R. P. Nair, T. Henseler, S. Jenisch, P. Stuart, C. K. Bichakjian, W. Lenk, et al., "Evidence for Two Psoriasis Susceptibility Loci (HLA and 17q) and Two Novel Candidate Regions (16q and 20p) by Genome-Wide Scan,"
Human Molecular Genetics, Vol. 6, No. 5, 1997, pp. 813-820

[8] A. Karason, J. E. Gudjonsson, R. Upmanyu, A. A. Antonsdottir, V. B. Hauksson, E. H. Runasdottir, et al., "A Susceptibility Gene for Psoriatic Arthritis Maps to Chromosome 16q: Evidence for Imprinting," The American Journal of Human Genetics, Vol. 72, No. 1, 2003, pp. 125-131. doi:10.1086/345646

[9] International Psoriasis Genetics Consortium, "The International Psoriasis Genetics Study: Assessing Linkage to 14 Candidate Susceptibility Loci in a Cohort of 742 Affected Sib Pairs," The American Journal of Human Genetics, Vol. 73, No. 2, 2003, pp. 430-437. doi:10.1086/377159

[10] R. C. Trembath, R. L. Clough, J. L. Rosbotham, A. B. Jones, R. D. Camp, A. Frodsham, et al., "Identification of a Major Susceptibility Locus on Chromosome 6p and Evidence for Further Disease Loci Revealed by a Two Stage Genome-Wide Search in Psoriasis," Human Molecular Genetics, Vol. 6, No. 5, 1997, pp. 813-820. doi:10.1093/hmg $/ 6.5 .813$

[11] R. P. Nair, K. C. Duffin, C. Helms, J. Ding, P. E. Stuart, D. Golgar, et al., "Genome-Wide Scan Reveals Association of Psoriasis with IL-23 and NF-KappaB Pathways," Nature Genetics, Vol. 41, No. 2, 2009, pp.199-204. doi:10.1038/ng.311

[12] M. C. Heng, S. G. Kloss and D. G. Chase, "Erythroderma Associated with Mixed Lymphocyte-Endothelial Cell Interaction and Staphylococcus aureus Infection," British Journal of Dermatology, Vol. 115, No. 6, 1986, pp. 693705. doi:10.1111/j.1365-2133.1986.tb06650.x

[13] B. J. Nikoloff, M. S. Mitra, J. Green, Y. Shimizu, C. Thompson and L. A. Turka, "Activated Keratinocytes Present Bacterial-Derived Superantigens to T Lymphocytes: Relevance to Psoriasis," Journal of Dermatological Science, Vol. 6, No. 2, 1993, pp. 127-133. doi:10.1016/0923-1811(93)90002-7

[14] H. Sigmundsdottir, B. Sigurgeirsson, M. Troye-Blomberg, M. F. Good, H. Valdemarsson and I. Jonsdottir, "Circulating T Lymphocytes of Patients with Active Psoriasis Respond to Streptococcal M Peptides Sharing Sequences with Human Epidermal Keratins," Scandinavian Journal of Immunology, Vol. 45, No. 6, 1997, pp. 688-697. doi:10.1046/j.1365-3083.1997.d01-438.x

[15] J. E. Gudjonsson, A. M. Thorainsson, B. Sigurgeirsson, K. G. Kristinsson and H. Valdimarsson, "Streptococcal Throat Infections and Exacerbation of Chronic Plaque Psoriasis: A Prospective Study," British Journal of Dermatology, Vol. 149, No. 3, 2004, pp. 530-534. doi:10.1046/j.1365-2133.2003.05552.x

[16] D. D. Balci, N. Duran, B. Ozer, R. Gunesacar, Y. Onlen and J. Z. Yennin, "High Prevalence of Staphylococcus aureus Cultivation and Superantigen Production in $\mathrm{Pa}$ tients with Psoriasis," European Journal of Dermatology, Vol. 19, No. 3, 2009, pp. 238-242.

[17] M. C. Heng, S. G. Kloss, C. S. Kuehn and D. G. Chase, "The Sequence of Events in Psoriatic Plaque Formation 
after Tape-Stripping," British Journal of Dermatology, Vol. 112, No., 1985, pp. 517-532.

[18] N. Hatta N, M. Takata, S. Kawara, T. Hirone and K. Takehara, "Tape-Stripping Induces Marked Epidermal Proliferation and Altered TGF-Alpha Expression in Non-lesional Psoriatic Skin," Journal of Dermatological Science, Vol. 14, No. 2, pp. 154-161.

[19] M. C. Heng, S. G. Allen, G. Haberfelde and M. K. Song, "Electron Microscopic and Immunocytochemical Study of the Sequence of Events in Psoriatic Plaque Formation after Tape-Stripping," British Journal of Dermatology, Vol. 125, No. 6, 1991, pp. 517-532. doi:10.1111/j.1365-2133.1991.tb14792.x

[20] E. Ferezli, L Jenbazian, N. Rubeiz, A. G. Kibbi, S. Zaynoun and A. M. Abdeinoor, "Streptococcus sp. and Staphylococcus aureus Isolates from Patients with Psoriasis Possess Genes that Code for Toxins (Superantigens): Clinical and Therapeutic Implications," Immunopharmacology and Immunotoxicology, Vol. 30, No. 2, 2008, pp. 195-205. doi:10.1080/08923970801946808

[21] M. R. Kell, E. G. Kavanaugh, A. Goebel, C. C. Soberg and J. A. Lederer, "Injury Primes the Immune System for an Enhanced and Lethal T Cell Response against Bacterial Superantigen," Shock, Vol. 12, No. 2, 1999, pp. 139144.

[22] S. Sriskandan, L. Faulkner and P. Hopkins, "Streptococcus Pyogenes: Insight into the Function of the Streptococcal Superantigens," The International Journal of Biochemistry \& Cell Biology, Vol. 39, No. 1, 2007, pp. 12-19. doi:10.1016/j.biocel.2006.08.009

[23] T. Proft and J. D. Fraser, "Streptococcal Superantigens," Chemical Immunology and Allergy, Vol. 93, 2007, pp. 1-23. doi:10.1159/000100851

[24] C. Bueno, G. Criado, J. K. McCormick and J. Madrenas, "T Cell Signaling Induced by Bacterial Superantigens," Chemical Immunology and Allergy, Vol. 93, 2007, pp. 161-180. doi:10.1159/000100894

[25] J. E. Alouf and H. Muller-Alouf, "Staphylococcal and Streptococcal Superantigens: Molecular, Biological and Clinical Aspects," International Journal of Medical Microbiology, Vol. 292, No. 7-8, 2003, pp. 429-440. doi:10.1078/1438-4221-00232

[26] F. W. Leung, M. C. Heng, S. Allen, K. Seno, J. W. Leung and M. K. Heng, "Involvement of Luminal Bacteria, Heat Shock Protein 60, Macrophages and $\gamma \delta$ T Cells in Dextran Sulfate Sodium-Induced Colitis in Rats," Digestive Diseases and Sciences, Vol. 45, No. 7, 2000, pp. 1472-1479. doi:10.1023/A:1005545128954

[27] C. J. Yuan, C. Y. Huang and D. J. Graves, "PhK: A Metal Ion-Dependent Dual Specificity Kinase," The Journal of Biological Chemistry, Vol. 268, No. 24, 1993, pp. 1768317686.

[28] D. Graves, C. Bartleson, A. Biorn and Pete M, "Substrate and Inhibitor Recognition of Protein Kinases: What Is Known about the Catalytic Subunit of Phosphorylase Kinase?" Pharmacology \& Therapeutics, Vol. 82, No. 2-3, 1999, pp. 43-155.
[29] M. C. Heng, M. K. Song and M. K. Heng, "Elevated Phosphorylase Kinase Activity in Psoriatic Epidermis: Correlation with Phosphorylation and Psoriatic Activity," British Journal of Dermatology, Vol. 130, No. 3, 1994, pp. 298-306. doi:10.1111/j.1365-2133.1994.tb02924.x

[30] M. C. Heng, M. K. Song, J. Harker and M. K. Heng, "Drug Induced Suppression of Phosphorylase Kinase Activity Correlates with Resolution of Psoriasis as Assessed by Clinical, Histological and Immunohistochemical Parameters," British Journal of Dermatology, Vol. 143, No. 5, 2000, pp. 937-949. doi:10.1046/j.1365-2133.2000.03767.x

[31] S. Reddy and B. B Aggarwal, "Curcumin Is a Non-Competitive and Selective Inhibitor of PhK," FEBS Letters, Vol. 341, No. 1, 1994, pp. 19-22. doi:10.1016/0014-5793(94)80232-7

[32] P. Scheunch, B. Thoma, U. Ucer and K. Pfizenmaier, "Immunoregulatory Activity of Recombinant Human Tumor Necrosis Factor (TNF)-Alpha: Induction of TNF Receptors on Human T Cells and TNF-Alpha-Mediated Enhancement of T Cell Responses," The Journal of Immunology, Vol. 138, No. 6, 1987, pp. 1786-1790.

[33] S. Singh and B. B. Aggarwal, "Activation of Transcription Factor NF-Kappa B Is Suppressed by Curcumin (Diferuloylmethane)," The Journal of Biological Chemistry, Vol. 270, No. 42, 1995, pp. 24995-25000. doi:10.1074/jbc.270.42.24995

[34] S. Aggarwal, H. Ichikawa, Y. Takada, S. K. Sandur, S. Shishodia and B. B. Aggarwal, "Curcumin (Diferuloylmethane) Downregulates Expression of Cell Proliferation and Antiapoptotic and Metastatic Gene Products through Suppression of IkappaBalpha Kinase and Akt Activation," Molecular Pharmacology, Vol. 69, No. 1, 2006, pp. 195-206.

[35] S. Tournier, F. P. Gerbaud, W. B. Anderson, S. M. Lohmann, D. Evain-Brion and F. Raynaud, "Post-Translational Abnormality of the Type II Cyclic AMP-Dependent Protein Kinase in Psoriasis: Modulation by Retinoic Acid," Journal of Cellular Biochemistry, Vol. 57, No. 4, 1995, pp. 647-654. doi:10.1002/jcb.240570409

[36] S. Tournier, F. Raynaud, P. Gerbaud, S. M. Lohmann, W. B. Anderson and D. Evain-Bion, "Retinoylation of the Type II Cyclic AMP-Binding Cyclic AMP-Dependent Protein Kinase is Increased in Psoriatic Human Fibroblasts," Journal of Cellular Physiology, Vol. 167, No. 2, 1996, pp. 196-203.

[37] Y. S. Cho-Chung and T. Clair, "The Regulatory Subunit of cAMP-Dependent Protein Kinase as a Target for Chemotherapy of Cancer and Other Cellular Dysfunctional-Related Diseases," Pharmacology \& Therapeutics, Vol. 60, No. 2, 1993, pp. 265-288. doi:10.1016/0163-7258(93)90010-B

[38] G. Sozzi, I. Bongarzone, M. Miozzo, M. G. Borrello, M. G. Blutti, S. Pilotti, et al., "A t(10:17) Translocation Creates the RET/PTC2 Chimeric Transforming Sequence in Papillary Thyroid Carcinoma," Genes, Chromosomes and Cancer, Vol. 9, No. 4, 1994, pp. 244-250. 


\section{doi: $10.1002 / \mathrm{gcc} .2870090404$}

[39] U. Francke, B. T. Darras, N. F. Zander and M. W. Kilimann, "Assignment of Human Genes for Phosphorylase Kinase Subunits Alpha (PHKA) to Xq12-q13 and Beta (PHKB) to 16q12-q13," The American Journal of Human Genetics, Vol. 45, No. 2, 1989, pp. 276-282.

[40] R. J. North and E. A. Havell, "Glucocorticoid-Mediated Inhibition of Endotoxin-Induced Intratumor Tumour Necrosis Factor Production and Tumour Hemorrhagic Necrosis and Regression," The Journal of Experimental Medicine, Vol. 170, No. 3, 1989, pp. 703-710.

[41] M. Tsujimoto and H. Adachi, "Effects of Steroid Hormones on the Cytotoxic Activity of Tumor Necrosis Factor," The Journal of Biochemistry, Vol. 103, No. 3, 1988, pp. 395-405.

[42] M. C. Heng, M. Khoo, A. Cooperman and S. FallonFriedlander, "Hemorrhagic Cellulitis: A Syndrome Associated with Tumour Necrosis Factor- $\alpha$," British Journal of Dermatology, Vol. 130, No. 1, 1994, pp. 65-74. doi:10.1111/j.1365-2133.1994.tb06885.x

[43] I. Neri, F. Bardazzi, S. Marzaduri and A. Patrizi, "Perianal Streptococcal Dermatitis in Adults," British Journal of Dermatology, Vol. 135, No. 5, 1996, pp. 796-798. doi:10.1111/j.1365-2133.1996.tb03894.x

[44] M. Ledoux, V. Chazerain, P. Saiag and E. Mahe, "Streptococcal Perianal Dermatitis and Guttate Psoriasis," Annales de Dermatologie et de Venereologie, Vol. 136, No. 1, 2009, pp. 37-41. doi:10.1016/j.annder.2008.06.013

[45] E. Mallon, M. Bunce, H. Savoie, A. Rowe, R. Newson, F. Gotch, et al., "HLA-C and Guttate Psoriasis," British Journal of Dermatology, Vol. 143, No. 6, 2000, pp. 11771182. doi:10.1046/j.1365-2133.2000.03885.x

[46] L. Malbris, K. Wolk, F. Sanchez and M. Stahle, "HLA$\mathrm{Cw}^{*} 0602$ Associates with a Twofold Higher Prevalence of Positive Streptococcal Throat Swab at the Onset of Psoriasis: A Case Control Study," BMC Dermatology, Vol. 29, No. 9, 2009, p. 5. doi:10.1186/1471-5945-9-5

[47] D. Y. Leung, J. B. Travers, R. Giorno, D. A. Norris, R. Skinner, J. Aelion, et al., "Evidence for a Streptococcal Superantigen-Driven Process in Acute Guttate Psoriasis," The Journal of Clinical Investigation, Vol. 96, No. 5, 1995, pp. 2106-2112.

[48] V. N. Saxena and J. Dogra, "Long-Term Use of Penicillin for the Treatment of Chronic Plaque Psoriasis," European Journal of Dermatology, Vol. 15, No. 5, 2005, pp. 359362.

[49] V. N. Saxena and J. Dogra, "Long-Term Oral Azithromycin in Chronic Plaque Psoriasis: A Controlled Trial," European Journal of Dermatology, Vol. 20, No. 3, 2010, pp. 329-333.

[50] R. G. El-Rachkidy, J. M. Hales, P. P. Freestone, H. S. Young, C. E. Griffiths and R. D. Camp, "Increased Blood Levels of IgG Reactive with Secreted Streptococcus Pyogenes Proteins in Chronic Plaque Psoriasis," Journal of Investigative Dermatology, Vol. 127, No. 6, 2007, pp.

\section{7-1342. doi:10.1038/sj.jid.5700744}

[51] H. Valdimarsson, H. Sigmundsdottir and I. Jonsdottir, "Is Psoriasis induced by Streptococcal Super Antigens and Maintained by M-Protein Specific T Cells That CrossReact with Keratin?" Clinical \& Experimental Immunology, Vol. 107, Supplement 1, 1997, pp. 21-24.

[52] U. Islander, A. Andersson, E. Lindberg, I. Adlerberth, A. E. Wold and A. Rudin, "Superantigenic Staphylococcus aureus Stimulate Production of Interleukin-17 from Memory but Not Naïve T Cells," Infection and Immunity, Vol. 78, No. 1, 2010, pp. 381-386. doi:10.1128/IAI.00724-09

[53] G. Fedele, M. Nasso, F. Spensieri, R. Palazzo, L. Frasca, M. Watanabe, et al., "Lipopolysaccharides from Bordetella pertussis and Bordetella parapertussis Differently Modulate Human Dendritic Cell Functions Resulting in Divergent Prevalence of Th17-Polarized Responses," The Journal of Immunology, Vol. 181, No. 1, 2008, pp. 208216.

[54] S. Iwamoto, S. Iwai, K. Tsujiyama, C. Kurahashi, K. Takeshita, M. Naoe, et al., "TNF-Alpha Drives Human CD14+ Monocytes to Differentiate into CD70+ Dendritic Cells Evoking Th1 and Th17 Responses," The Journal of Immunology, Vol. 179, No. 3, 2007, pp. 1449-1457.

[55] S. Siegemund, N. Schutze, M. A. Freudenberg, M. B. Lutz, R. K. Staubinger and G. Alber, "Production of IL-12, IL-23 and IL-27p28 by Bone Marrow-Derived Conventional Dendritic Cells Rather than Macrophages after LPA/TLR4-Dependent Induction by Salmonella Enteritidis," Immunobiology, Vol. 212, No. 9-10, 2007, pp. 739-750. doi:10.1016/j.imbio.2007.09.004

[56] C. Abraham and J. Cho, "Interleukin-23/Th17 Pathways and Inflammatory Bowel Disease," Inflammatory Bowel Diseases, Vol. 15, No. 7, 2009, pp. 1090-1100. doi:10.1002/ibd.20894

[57] C. O. Elson, Y. Cong, C. T. Weaver, T. R. Schoeb, T. K. McClanahan, R. B. Fick, et al., "Monoclonal Anti-interleukin 23 Reverses Active Colitis in a T Cell-Mediated Model in Mice," Gastroenterology, Vol. 132, No. 7, 2007, pp. 2359-2370. doi:10.1053/j.gastro.2007.03.104

[58] Z. Liu, J. Jiu, S. Liu, X. Fa, F. Li and Y. Du, "Blockage of Tumor Necrosis Factor Prevents Intestinal Mucosal Inflammation through down-Regulation of Interleukin-23 Secretion," Journal of Autoimmunity, Vol. 29, No. 2-3, 2007, pp. 187-194. doi:10.1016/j.jaut.2007.07.004

[59] A. Di Cesare, P. Mi-Meglio and F. O. Nestle, "The IL-23/Th17 Axis in the Immunopathogenesis of Psoriasis," Journal of Investigative Dermatology, Vol. 129, No. 6, 2009, pp. 1339-1350. doi:10.1038/jid.2009.59

[60] C. Ortega, S. Fernandez-A, J. M. Carrillo, P. Romero, I. J. Molina, J. C. Moreno, et al., "IL-17 Producing CD8+ T Lymphocytes from Psoriatic Skin Plaques Are Cytotoxic Effector Cells That Secrete Th17-Related Cytokines," Journal of Leukocyte Biology, Vol. 86, No. 2, 2009, pp. 435-443. doi:10.1189/JLB.0109046

[61] J. H. Saurat, G. Stingl, L. Dubertret, K. Papp, R. G. 
Langley, J. P. Ortonne, et al., "Efficacy and Safety Results from the Randomized Controlled Comparative Study of Adalimumab vs Methotrexate vs Placebo in Patients with Psoriasis (CHAMPION)," British Journal of Dermatology, Vol. 158, No. 3, 2008, pp. 556-566.

[62] W. Sterry, J. P. Ortonne, B. Kirkham, O. Brocq, D. Robertson, R. D. Pedersen, et al., "Comparison of Two Etanercept Regimens for Treatment of Psoriatic Arthritis: PRESTA Randomized Double Blind Multicenter Trial," British Medical Journal, Vol. 340, 2010, p. c147. doi:10.1136/bmj.c147

[63] S. N. Al-Surwaidan and S. R. Feldman, "Clearance is Not a Realistic Expectation of Psoriasis Treatment," Journal of the American Academy of Dermatology, Vol. 42, No. 5, 2000, pp. 796-802. doi:10.1067/mjd.2000.103983

[64] F. C. Victor, A. B. Gottlieb and A. Menter, "Changing Paradigms in Dermatology: Tumor Necrosis Factor Alpha (TNF-Alpha) Blockade in Psoriasis and Psoriatic Arthritis," Clinics in Dermatology, Vol. 21, No. 5, 2003, pp. 392-397. doi:10.1016/j.clindermatol.2003.08.015

[65] D. Tsurula, "NF-KappaB Links Keratinocytes and Lymphocytes in the Pathogenesis of Psoriasis," Recent Patents on Inflammation \& Allergy drug Discovery, Vol. 3, No. 1, 2009, pp. 40-48. doi: $10.2174 / 187221309787158399$ 